University of Nebraska - Lincoln

DigitalCommons@University of Nebraska - Lincoln

Si-Hwang Liou Publications

Research Papers in Physics and Astronomy

March 1984

\title{
Mössbauer study of sputtered Fe-Ti alloys with wide composition range
}

Sy_Hwang Liou

University of Nebraska-Lincoln, sliou@unl.edu

C.L. Chien

John Hopkins University, Baltimore, Maryland

Follow this and additional works at: https://digitalcommons.unl.edu/physicsliou

Part of the Physics Commons

Liou, Sy_Hwang and Chien, C.L., "Mössbauer study of sputtered Fe-Ti alloys with wide composition range" (1984). Si-Hwang Liou Publications. 4.

https://digitalcommons.unl.edu/physicsliou/4

This Article is brought to you for free and open access by the Research Papers in Physics and Astronomy at DigitalCommons@University of Nebraska - Lincoln. It has been accepted for inclusion in Si-Hwang Liou Publications by an authorized administrator of DigitalCommons@University of Nebraska - Lincoln. 


\title{
Mössbauer study of sputtered Fe-Ti alloys with wide composition range
}

\author{
S. H. Liou and C. L. Chien \\ Department of Physics, The Johns Hopkins University, Baltimore, Maryland 21218
}

$\mathrm{Fe}_{x} \mathrm{Ti}_{100-x}$ alloys over a wide composition range has been made by high-rate sputtering and studied by ${ }^{57} \mathrm{Fe}$ Mössbauer spectroscopy. Samples with $30 \leqslant x \leqslant 80$ are amorphous whereas samples with $x \geqslant 85$ are metastable crystalline bcc alloys. Large differences in magnetic properties (e.g., $\left.T_{C}\right)$ and hyperfine interactions ( $H_{\text {eff }}$, isomer shift) are found between the amorphous and bcc alloys. Comparison of $\mathrm{FeTi}$ and $\mathrm{Fe}_{2} \mathrm{Ti}$ in amorphous and crystalline states show that the shortrange order in the amorphous state has no resemblence to that of the crystalline compounds.

PACS numbers: $75.50 . \mathrm{Kj}, 76.80 .+\mathrm{y}, 75.50 . \mathrm{Bb}$

\section{INTRODUCTION}

Under equilibrium conditions, solids containing $\mathrm{Fe}$ and $\mathrm{Ti}$ exist as crystalline intermetallic compounds ( $\mathrm{FeTi}$ and $\mathrm{Fe}_{2} \mathrm{Ti}$ ) and low solubility (a few percent) alloys. ${ }^{1-3} \mathrm{We}$ show in this work that by using a vapor-quench method, $\mathrm{Fe}_{x} \mathrm{Ti}_{100-x}$ alloys can be fabricated over the wide composition range of $30 \leqslant x \leqslant 100$. Depending on the composition, the alloy appears either as a crystalline bcc structure or an amorphous solid. ${ }^{4,5}$ Very different magnetic properties and hyperfine interactions have been observed between the crystalline and amorphous alloys. Mössbauer results indicate that the local short range order in the amorphous state has no resemblence to that of crystalline $\mathrm{FeTi}$ and $\mathrm{Fe}_{2} \mathrm{Ti}$.

\section{EXPERIMENT}

$\mathrm{Fe}_{x} \mathrm{Ti}_{100-x}(30 \leqslant x \leqslant 100)$ films, $5-10 \mu \mathrm{m}$ in thickness, were deposited by a high-rate sputtering device onto liquid nitrogen cooled Kapton or Cu substrates. ${ }^{6}$ The samples with $30 \leqslant x \leqslant 80$ are amorphous, whereas the samples with $x \geqslant 85$ are metastable crystalline bcc alloys. Using an energy dispersive $\mathrm{x}$-ray diffraction method, the bcc structure of the samples with $x \geqslant 85$ is ascertained. The lattice parameters of these bcc alloys are very close to that of $\alpha-\mathrm{Fe}$. The crystalline intermetallic compounds of $\mathrm{FeTi}$ and $\mathrm{Fe}_{2} \mathrm{Ti}$ were made by arc melting in an argon atmosphere. A ${ }^{57} \mathrm{Co}$ in $\mathrm{Rh}$ source was used in a conventional Mössbauer spectrometer.

\section{RESULTS AND DISCUSSIONS}

At ambient temperatures, the solubility of $\mathrm{Ti}$ in bcc $\mathrm{Fe}$ is only about 4 at. \%. ${ }^{3}$ Through vapor quenching, the solubility in the bcc state is substantially extended to at least 15 at. $\%(x \geqslant 85)$. At higher Ti contents $(30 \leqslant x<80)$, the sputtered samples are amorphous. As described in the following, the properties of the amorphous alloys and the bcc alloys are very different. Consequently, there are abrupt changes in properties at the boundary separating the amorphous state and the crystalline bcc state. The large composition range of the amorphous state covers the compositions corresponding to crystalline $\mathrm{FeTi}$ and $\mathrm{Fe}_{2} \mathrm{Ti}$. One can therefore directly compare $\mathrm{FeTi}$ and $\mathrm{Fe}_{2} \mathrm{Ti}$ in both crystalline and amorphous state.

\section{A. Magnetic ordering'temperature $\left(T_{C}\right)$}

The magnetic ordering temperatures of the amorphous samples $(30 \leqslant x \leqslant 80)$ have been determined by the zero veloc- ity thermal scan method. The measured values of $T_{C}$, all below room temperature, increase monotonically with $x$ as shown in Fig. 1. Below the magnetic threshold of $x_{c} \simeq 43$, the low $\mathrm{Fe}$ concentration samples are nonmagnetic. On the other hand, the values of $T_{C}$ for the metastable bcc alloys $(x \geqslant 85)$ are very much higher than room temeprature. Due to structural transformation of these metastable alloys at high temperatures, their $T_{C}$ can not be directly measured. Nevertheless, the values of $T_{C}$ are substantially higher than $850 \mathrm{~K}$, above which the samples transform irreversably.

\section{B. Magnetic hyperfine interaction}

Mössbauer spectra of amorphous $\mathrm{Fe}_{75} \mathrm{Ti}_{25}$ and $\mathrm{Fe}_{80} \mathrm{Ti}_{20}$ at $4.2 \mathrm{~K}$ are shown in Fig. 2. Despite relatively high Fe content, the effective magnetic hyperfine field $\left(H_{\text {eff }}\right)$ and therefore the Fe magnetic moment are rather small. ${ }^{5}$ As shown in Fig. 3, the value of $H_{\text {eff }}$ of amorphous Fe-Ti decreases monotonically as the Fe concentration is reduced, and is extrapolated to zero at about the magnetic threshold of $x_{c} \simeq 43 \mathrm{ob}$ served in Fig. 1. This indicates, as already observed in many binary amorphous $\mathrm{Fe}$-containing alloys, such $\mathrm{Fe}-\mathrm{B}, \mathrm{Fe}-\mathrm{Nb}$, $\mathrm{Fe}-\mathrm{Zr}$, etc., that the disappearance of $\mathrm{Fe}$ moment causes the samples with $x<x_{c}$ to be nonmagnetic. ${ }^{6-8}$

Completely different spectra are observed for the metastable bcc Fe-Ti alloys. The bottom figure of Fig. 2 shows the spectrum of the as-prepared bcc $\mathrm{Fe}_{85} \mathrm{Ti}_{15}$ alloy at $4.2 \mathrm{~K}$. The splitting and correspondingly the value of $H_{\text {eff }}$ are much larger than those of the amorphous Fe-Ti alloys. As shown

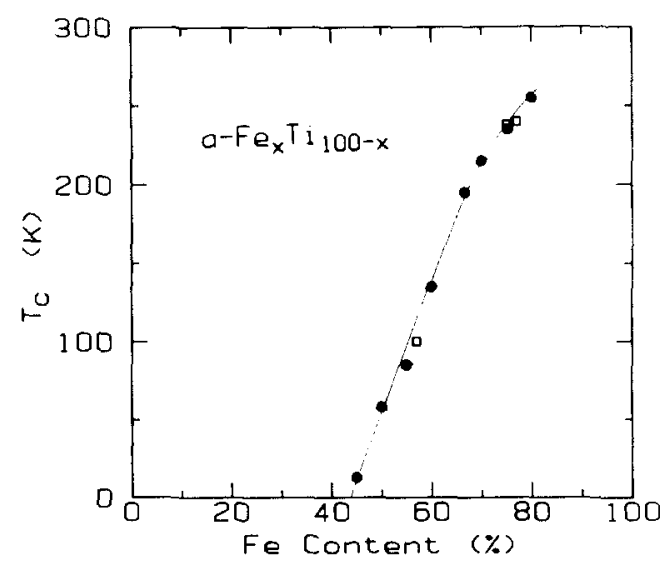

FIG. 1. Magnetic ordering temperatures of amorphous Fe-Ti alloys. The open squares are taken from Ref. 4 . 

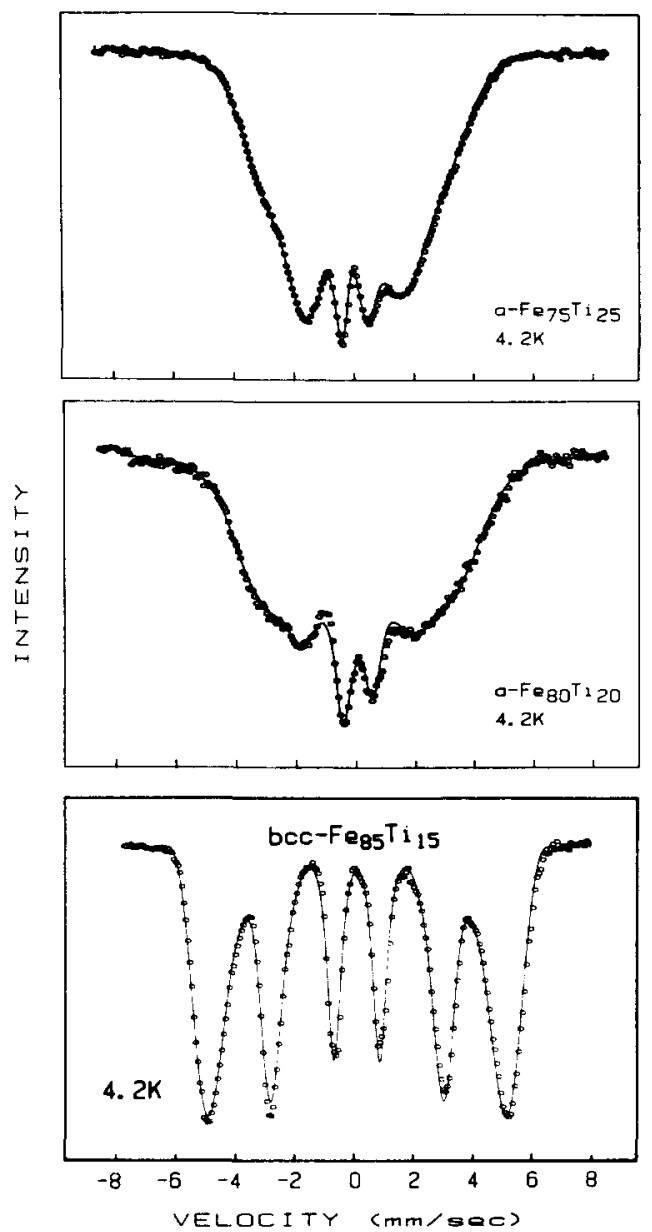

FIG. 2. Mössbauer spectra of amorphous $\mathrm{Fe}_{75} \mathrm{Ti}_{25}, \mathrm{Fe}_{80} \mathrm{Ti}_{30}$, and crystalline bcc $\mathrm{Fe}_{85} \mathrm{Ti}_{15}$ at $4.2 \mathrm{~K}$.

in Fig. 3, from amorphous $\mathrm{Fe}_{80} \mathrm{Ti}_{20}$ to bcc $\mathrm{Fe}_{85} \mathrm{Ti}_{15}$, there is an abrupt increase in $H_{\text {eff }}$ of about $50 \%$. Sumiyama et al. have observed a similarly large increase in the Fe moment. ${ }^{5}$

At elevated temperatures, the metastable bcc Fe-Ti alloys transform irreversible into $\alpha$ - $\mathrm{Fe}$ and $\mathrm{Fe}_{2} \mathrm{Ti}$.

\section{Quadrupole spectra}

At room temperature, all the amorphous Fe-Ti samples exhibit quadrupole spectra, from which values of isomer

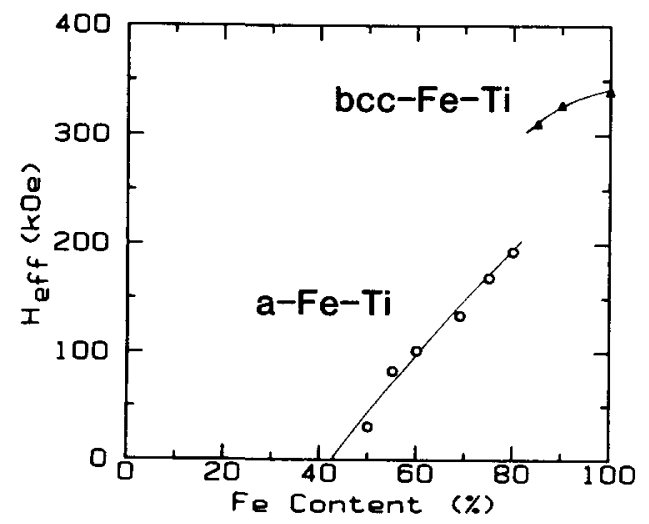

FIG. 3. Magnetic hyperfine field $\left(H_{\text {eff }}\right)$ at $4.2 \mathrm{~K}$ of amorphous and bcc Fe-Ti alloys.

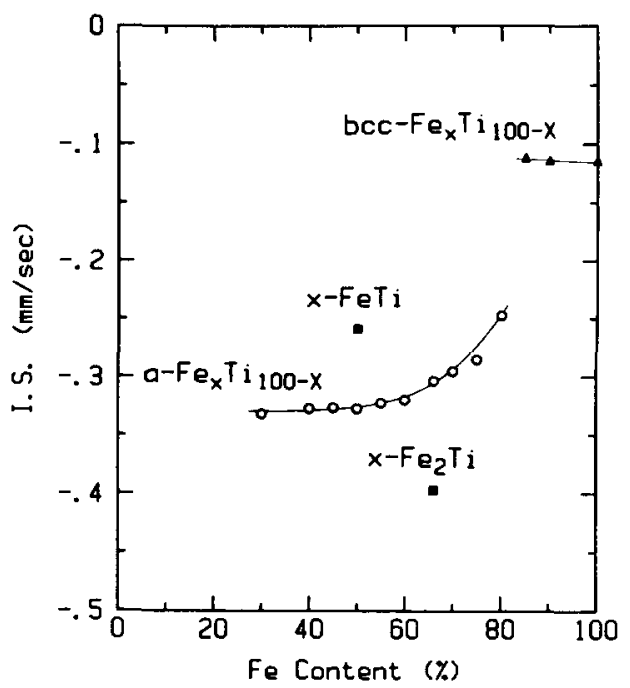

FIG. 4. Isomer shifts of amorphous and bcc Fe-Ti alloys and crystalline $\mathrm{FeTi}$ and $\mathrm{Fe}_{2} \mathrm{Ti}$ at room temperature.

shift and quadrupole splitting can be determined. The isomer shift of amorphous and bcc Fe-Ti alloys are shown in Fig. 4. The isomer shifts of the amorphous alloys, like other amorphous Fe-transition metal alloys, are negative with respect to $\alpha$-Fe. ${ }^{7-8}$ The isomer shifts of the bcc alloys are essentially the same as that of $\alpha-\mathrm{Fe}$. Most noticeably, there is a very large difference between the isomer shifts of amorphous and bec Fe-Ti alloys.

The quadrupole splitting of the amorphous $\mathrm{Fe}$-Ti alloys are shown in Fig. 5. These values, similar to other amorphous Fe-early transition metal alloys, decrease with $\mathrm{Fe}$ content and exhibit a shallow minimum at $x \simeq 70$.

\section{Comparison of crystalline and amorphous FeTi and $\mathrm{Fe}_{2} \mathrm{Ti}$}

In the crystalline Fe-Ti system, there are only two intermetallic compounds ( $\mathrm{FeTi}$ and $\mathrm{Fe}_{2} \mathrm{Ti}$ ), both with well-known properties and crystal structures. Crystalline $\mathrm{FeTi}(x-\mathrm{FeTi})$ has a simple (B2) $\mathrm{CsCl}$ structure with cubic symmetry. The Mössbauer spectrum consequently shows zero quadrupole splitting. Crystalline $\mathrm{Fe}_{2} \mathrm{Ti}\left(x-\mathrm{Fe}_{2} \mathrm{Ti}\right)$ has a $(\mathrm{C}-14) \mathrm{MgZn}_{2}$ structure. ${ }^{1}$ The Mössbauer spectrum shows a large quadru-

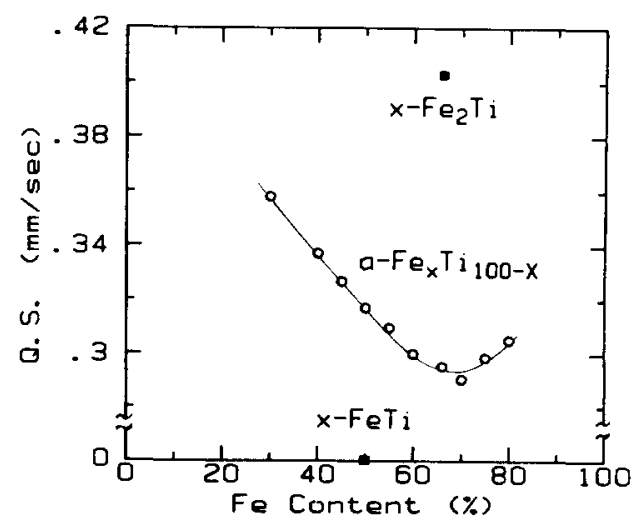

FIG. 5. Quadrupole splittings of amorphous Fe-Ti alloys and crystalline $\mathrm{FeTi}$ and $\mathrm{Fe}_{2} \mathrm{Ti}$ at room temperature. 
pole splitting of $0.40 \mathrm{~mm} / \mathrm{sec}$. These values, in good agreement with those in the literature, are shown in Figs. 4 and 5. It is clear that these values are distinctively different from those of $a$-FeTi and $a$-Fe 2 Ti; in fact, amorphous Fe-Ti of all compositions.

\section{CONCLUSIONS}

The results of amorphous and bcc Fe-Ti alloys illustrate that the magnetic properties and hyperfine interactions depend sensitively on the structure. Abrupt changes occur near the boundary separating the amorphous and the crystalline bcc states.

The comparison of FeTi and $\mathrm{Fe}_{2} \mathrm{Ti}$ in amorphous and crystalline states provide insights of the local charge distributions and atomic arrangements. The isomer shifts and quadrupole splitting are so far apart that they provide evidences against the conjecture that similar local short-range order may be found in both amorphous and crystalline states.

\section{ACKNOWLEDGMENT}

This work was supported by the National Science Foundation Grant No. DMR82-05135.

${ }^{\text {I}}$ G. K. Wertheim, J. H. Wernick, and R. C. Sherwood, Solid State Commun. 7, 1399 (1969).

${ }^{2}$ A. Bläsius and U. Gonser, Appl. Phys. 22, 331 (1980).

${ }^{3}$ T. Mizuno and T. Morozuni, J. Less Common Metals 84, 237 (1982).

${ }^{4}$ K. Fukamichi, H. Hiroyoshi, T. Kaneko, T. Masumoto, and K. Shirakawa, J. Appl. Phys. 53, 8107 (1982).

${ }^{5}$ K. Sumiyama, Y. Hashimoto, T. Yoshitake, and Y. Nakamura, J. Magn. Magn. Mater. 31-34, 1495 (1983).

${ }^{6} \mathrm{C}$. L. Chien and K. M. Unruh, Phys. Rev. B 25, 5790 (1982).

${ }^{7}$ C. L. Chien, K. M. Unruh, and S. H. Liou, J. Appl. Phys. 53, 7756 (1982).

${ }^{8}$ K. M. Unruh and C. L. Chien, J. Magn. Magn. Mater. 31-34, 1578 (1983). 